\title{
Iogurte probiótico com frutanos tipo inulina de diferentes graus de polimerização: características físico-químicas e microbiológicas e estabilidade ao armazenamento
}

\section{Probiotic yoghurt with inulin-type fructans of different degrees of polymerization: physicochemical and microbiological characteristics and storage stability}

\author{
Tatiana Colombo Pimentel ${ }^{1}$; Sandra Garcia²; Sandra Helena Prudencio ${ }^{3 *}$
}

\section{Resumo}

\begin{abstract}
Investigou-se o efeito da adição de frutanos tipo inulina de diferentes graus de polimerização (DP) nas características físico-químicas e microbiológicas e na estabilidade ao armazenamento $\left(4^{\circ} \mathrm{C}\right.$ por 28 dias) de iogurtes probióticos desnatados. Os iogurtes foram preparados usando cultura lática tradicional (Streptococcus thermophilus e Lactobacillus delbrueckii ssp. bulgaricus) e Lactobacillus paracasei ssp. paracasei como probiótico. As formulações continham frutanos tipo inulina de DP: baixo (oligofrutose P95, DP 5), médio (inulina ST, DP 10) ou alto (inulina HP, DP 23), em uma concentração de $2 \mathrm{~g} 100 \mathrm{~g}$ de leite ${ }^{-1}$, de modo a atender a legislação brasileira vigente e assim, utilizar sua alegação de propriedade funcional; e foram comparadas a uma formulação Normal (sem adição de frutanos tipo inulina). A adição de frutanos tipo inulina com diferente DP não alterou os parâmetros $L^{*}$, a* e b* de cor, a sinérese e a viabilidade da cultura probiótica dos iogurtes. Iogurtes com frutanos tipo inulina de baixo DP foram mais ácidos (menores valores de $\mathrm{pH}$ e maiores valores de acidez titulável). A inulina de alto DP ocasionou redução na firmeza dos iogurtes. Os produtos continham Lactobacillus paracasei ssp. paracasei em concentrações superiores às recomendadas para considerá-los como sendo probióticos durante todo o período de armazenamento. $\mathrm{O}$ armazenamento refrigerado resultou em diminuição do pH e da viabilidade da cultura probiótica e aumento da acidez titulável e da sinérese dos iogurtes, independentemente da utilização de frutanos tipo inulina. Conclui-se que a adição de frutanos tipo inulina de diferente DP não afeta negativamente as características físico-químicas e microbiológicas dos iogurtes e sua estabilidade ao armazenamento; sendo assim, a seleção do tipo a ser utilizado dependerá do objetivo do fabricante e da intenção de uso.
\end{abstract}

Palavras-chave: Prebiótico, Lactobacillus paracasei, inulina, oligofrutose

\begin{abstract}
The effect of the addition of inulin-type fructans of different degrees of polymerization (DP) on the physicochemical and microbiological characteristics and storage stability $\left(4^{\circ} \mathrm{C}\right.$ for 28 days) of nonfat probiotic yoghurt was investigated. The yoghurts were prepared using traditional lactic culture (Streptococcus thermophilus and Lactobacillus delbrueckii ssp. bulgaricus) and Lactobacillus paracasei ssp. paracasei as probiotic. The formulations contained inulin- type fructans of DP: low (P95 oligofructose, DP 5), medium (ST inulin, DP 10) or high (HP inulin, DP 23) in a concentration of $2 \mathrm{~g}$

\footnotetext{
${ }^{1}$ Eng $^{\text {a }}$ de Alimentos, Ms. Doutoranda em Ciência de Alimentos pela Universidade Estadual de Londrina, UEL, Londrina, PR. E-mail: tatipimentel@hotmail.com

${ }^{2}$ Enga de Alimentos, Prof ${ }^{a}$ Dr $^{\mathrm{a}}$ Associada da UEL, Londrina, PR. E-mail: sgarcia@uel.br

${ }^{3}$ Farmacêutica-Bioquímica, Prof ${ }^{a}$ Dr $^{\mathrm{a}}$. Associada da UEL, Londrina, PR. E-mail: sandrah@uel.br

* Autor para correspondência
} 
$100 \mathrm{~g}$ of milk $\mathrm{k}^{-1}$, meeting the current Brazilian legislation and, thus their claim of functional properties could be utilized; and were compared to a Normal formulation (without inulin-type fructans addition). The addition of inulin-type fructans with different DP did not alter the $\mathrm{L}^{*}, \mathrm{a}^{*}$ and $\mathrm{b}^{*}$ color parameters, the syneresis and the viability of the probiotic culture in yoghurts. Yoghurts with inulin-type fructans of low DP were more acidic (lower $\mathrm{pH}$ values and higher values of acidity). The high DP inulin caused a reduction in the firmness of yoghurt. The products contained Lactobacillus paracasei ssp. paracasei at concentrations higher than that recommended to consider them as probiotic foods throughout the storage period. The refrigerated storage resulted in decreased $\mathrm{pH}$ and viability of the probiotic culture and increased acidity and syneresis of yoghurt, regardless of the use of inulin-type fructans. It can be concluded that the addition of inulin-type fructans of different DP does not adversely affect the physicochemical and microbiological characteristics of yoghurts and their stability to storage, thus, the selection of the type to be used depend on the purpose of the manufacturer and the intended use.

Key words: Prebiotic, Lactobacillus paracasei, inulin, oligofructose

\section{Introdução}

Probióticos são microorganismos vivos que conferem efeito benéfico ao indivíduo quando consumidos em quantidades adequadas (FAO/ WHO, 2001). Tem sido reportado que o L. casei estimula o sistema imune (ARYANA; McGREW, 2007; DONG et al., 2010); alivia os sintomas de doença de Crohn (INGRASSIA; LEPLINGARD; DARFEUILLE-MICHAUD， 2005); reduz os sinais clínicos de diarréia por rotavírus (GUÉRINDANAN et al., 2001); diminui os níveis de triglicérides séricos e colesterol (MINELLI et al., 2004) e possui propriedades antimicrobianas (SGOURAS et al., 2004; MONADI et al., 2010).

Prebióticos são componentes alimentares não viáveis que conferem benefícios à saúde do hospedeiro associados à modulação de sua microbiota (FAO/ AGNS, 2007). Prebióticos não são digeridos no trato gastrintestinal superior devido à inabilidade enzimática humana, portanto, agem como fibras solúveis e são fermentados no cólon, aumentando a atividade microbiana e estimulando o crescimento preferencial de bifidobactérias e lactobacilos (SAXELIN; KORPELA; MAYRAMAKINEN, 2003). Outros benefícios à saúde desses componentes seriam: diminuição no nível de colesterol sérico (SANDERS, 2003; DE LUIS et al., 2011); inibição de substâncias mutagênicas e redução da incidência de tumores intestinais (SHEIL; SHANAHAN; O’MAHONY, 2007); metabolismo da lactose e redução da intolerância à lactose (SANDERS, 2003) e aumento na absorção de minerais, como o cálcio (KAUR; GUPTA, 2002; VAZ et al., 2010).

Frutanos tipo inulina são os principais compostos com propriedades prebióticas, sendo caracterizados como polímeros onde uma ou mais ligações frutosil-frutose representam a maioria das ligações glicosídicas, e incluem a inulina e as oligofrutoses. Seu grau de polimerização (DP) representa o número de monossacarídeos que compõe a molécula e pode influenciar propriedades destes ingredientes, como digestibilidade, atividade prebiótica, poder adoçante, capacidade de absorção de água, etc (ROBERFROID, 2005; KELLY, 2008).

O termo inulina é uma descrição de misturas de frutanos tipo inulina que contenham pelo menos algumas cadeias com DP maior do que 10. Inulinas de maior grau de polimerização (DP 22 a 25) são obtidas por meio da remoção física das moléculas de cadeia curta. Oligofrutoses são os frutanos tipo inulina de DP $<10$ produzidos por hidrólise parcial da inulina (ROBERFROID, 2005; KELLY, 2008).

Frutanos tipo inulina são utilizados como ingredientes no desenvolvimento de novos produtos não apenas por suas propriedades nutricionais, mas também devido a razões tecnológicas (TÁRREGA; COSTELL, 2006). A inulina pode ser utilizada como substituto de gordura em alimentos, pois possui a capacidade de promover na boca uma sensação tátil oral semelhante à da gordura. Seu maior peso molecular quando comparado ao das oligofrutoses 
torna-a menos solúvel e com habilidade de formar microcristais quando misturada à água ou leite. Esses microcristais não são percebidos na boca, mas interagem para formar uma textura finamente cremosa (NINESS, 1999; FRANCK, 2002).

Oligofrutoses têm propriedades comparáveis às do açúcar e xaropes de glicose, por possuírem maior quantidade de açúcares livres. A doçura na forma pura é de 30 a 35\% quando comparada à sacarose, consequentemente são combinadas com edulcorantes para se obter níveis de doçura desejáveis e mascarar seus possíveis sabores residuais (COUSSEMENT, 1999; FRANCK, 2002).

A utilização de prebióticos pode resultar em alterações dos atributos de qualidade de produtos lácteos devido a interações entre o ingrediente funcional e os componentes da matriz alimentar (CRUZ et al., 2010). Há pouca informação na literatura acerca do efeito do grau de polimerização de frutanos tipo inulina nas propriedades físicoquímicas e na viabilidade de culturas probióticas em produtos lácteos. Portanto, o objetivo do presente trabalho foi avaliar o efeito da adição de frutanos tipo inulina de diferentes graus de polimerização nas características físico-químicas e microbiológicas e na estabilidade ao armazenamento de iogurtes desnatados probióticos.

\section{Material e Métodos}

\section{Ingredientes e culturas}

Leite em pó desnatado (Molico, Nestlé, São Paulo, Brasil) de mesmo lote foi utilizado em todo o experimento. A cultura lática, contendo Lactobacillus delbrueckii ssp. bulgaricus e Streptococcus thermophilus (YC X-11) e a cultura probiótica Lactobacillus paracasei ssp. paracasei (L. casei-01)(Chr. Hansen, Valinhos, Brasil) estavam na forma liofilizada (DVS) e foram armazenadas a $-20^{\circ} \mathrm{C}$, de acordo com as recomendações do fabricante. Os frutanos tipo inulina utilizados foram de graus de polimerização: baixo (oligofrutose P95,
DP médio 5), médio (inulina ST, DP médio 10), e alto (inulina HP, DP médio 23) (Orafti, Oreye, Bélgica).

\section{Preparação dos iogurtes}

Quatro formulações foram preparadas: Normal (iogurte probiótico); P95 (iogurte probiótico adicionado de oligofrutose P95); ST (iogurte probiótico adicionado de inulina ST) e, HP (iogurte probiótico adicionado de inulina HP).

Leite em pó desnatado foi reconstituído a $13 \mathrm{~g} \mathrm{~L}^{-1}$ com água destilada. A fim de manter o teor de sólidos totais constante, na formulação Normal foram adicionados $35 \mathrm{~g} \mathrm{~L}^{-1}$ de leite em pó desnatado, enquanto nas formulações P95, ST e HP foram adicionados $15 \mathrm{~g} \mathrm{~L}^{-1}$ de leite em pó desnatado e $20 \mathrm{~g} \mathrm{~L}^{-1}$ de oligofrutose P95, inulina ST ou inulina HP, respectivamente (AKALIN; FENDERYA; AKBULUT, 2004). As misturas foram pasteurizadas a $85^{\circ} \mathrm{C}$ por 30 minutos e resfriadas a $42^{\circ} \mathrm{C}$ (AKALIN; FENDERYA; AKBULUT, 2004). A seguir, foram inoculadas $0,1 \mathrm{U} \mathrm{L} \mathrm{L}^{-1}$ da cultura lática (Lactobacillus delbrueckii ssp. bulgaricus e Streptococcus thermophilus) e $0,1 \mathrm{~g} \quad \mathrm{~L}^{-1}$ de Lactobacillus paracasei ssp. paracasei. As culturas foram utilizadas de acordo com as instruções do fabricante. As bases inoculadas foram colocadas em recipientes de plástico com tampa e capacidade para $80 \mathrm{~mL}$, incubadas a $42^{\circ} \mathrm{C}$ até que o $\mathrm{pH} 4,5$ fosse alcançado, resfriadas a $4^{\circ} \mathrm{C}$ e armazenadas nessa temperatura por 28 dias (DONKOR et al., 2007).

A quantidade de frutanos tipo inulina adicionada foi baseada na regulamentação brasileira a fim de se utilizar sua alegação de propriedade funcional (ANVISA, 2008), considerando ingestão de 100 gramas diários do produto. A quantidade de Lactobacillus paracasei ssp. paracasei adicionada correspondia a $10^{11}$ células viáveis em $1 \mathrm{~L}$ de produto final.

Os iogurtes de cada formulação foram analisados no primeiro dia e após 14 e 28 dias de 
armazenamento. As análises de viabilidade da cultura probiótica e de sinérese foram realizadas em duplicata, enquanto as análises físico-químicas foram feitas em triplicata.

\section{pH e acidez titulável}

Determinou-se o $\mathrm{pH}$ dos iogurtes usando um potenciômetro digital (Tecnal Tec 3MP, Piracicaba, São Paulo, Brasil) previamente calibrado com tampões fosfato $\mathrm{pH}$ 4,0 e 7,0. A acidez titulável foi determinada segundo a AOAC (1995) e expressa em porcentagem (\%) de ácido lático.

\section{Cor}

Para avaliação instrumental da cor utilizouse colorímetro BYK Gardner (Germany, série 199968). O aparelho tinha como especificação: área de leitura $11 \mathrm{~mm}$, iluminante D65 (luz natural do dia), iluminação em um ângulo de $45^{\circ}$, ângulo de observação de $0^{\circ}$ e observador padrão $\mathrm{CIE} 10^{\circ}$. O colorímetro forneceu diretamente os parâmetros $\mathrm{L}^{*}$ (luminosidade), a* (componente vermelho-verde) e $b^{*}$ (componente amarelo-azul).

\section{Firmeza}

Para a análise de firmeza as formulações, em seus recipientes originais, foram submetidas ao texturômetro TA-XT2i (Stable Micro Systems, Godalming, Surrey, Inglaterra), utilizando-se sensor cilíndrico de acrílico P $25 / \mathrm{L}$, profundidade de compressão de $8 \mathrm{~mm}$; velocidade de compressão do sensor de $2 \mathrm{~mm} \mathrm{~s}^{-1}$; força de $0,10 \mathrm{~N}$ e tempo de 0,5 segundos. A firmeza do gel (N) foi obtida a partir das curvas força $\mathrm{x}$ tempo e área dos gráficos.

\section{Sinérese}

O soro liberado das formulações de iogurte foi medido de acordo com Aryana (2003), com modificações. Foi feita a inversão de 3 recipientes contendo iogurte a $8^{\circ} \mathrm{C}$ em uma peneira colocada no topo de um funil. A quantidade de soro coletada em um cilindro graduado após 2 horas a $21^{\circ} \mathrm{C}$ foi usada como indicador da capacidade de retenção de água da formulação (volume de soro por 100 gramas de amostra).

\section{Viabilidade da cultura probiótica}

Um (1) mililitro de cada formulação de iogurte foi diluído em $9 \mathrm{~mL}$ de água peptonada $0,1 \%$ $(\mathrm{p} / \mathrm{v})$ (Oxoid, Basingstoke, Inglaterra) esterilizada e agitado uniformemente com um agitador. As diluições seriadas foram realizadas e o número de microorganismos viáveis da cultura probiótica enumerados usando a técnica de pour plate. A contagem de Lactobacillus paracasei ssp. paracasei foi feita em ágar vancomicina de acordo com Tharmaraj e Shah (2003). Aproximadamente $2 \mathrm{~mL}$ de uma solução de $0,05 \mathrm{~g}$ vancomicina 100 $\mathrm{mL}$ de solução ${ }^{-1}$ foram adicionados a $1000 \mathrm{~mL}$ de ágar MRS (Himedia, Mumbai, Índia) esterilizado para obter $1 \mathrm{mg} \mathrm{L}^{-1}$ de concentração final. A solução de vancomicina foi esterilizada previamente por filtração em membrana Millipore $0,45 \mu \mathrm{m}$. Incubação anaeróbica a $37^{\circ} \mathrm{C}$ por 72 horas foi utilizada.

\section{Análise Estatística}

O experimento completo foi repetido duas vezes seguindo delineamento inteiramente casualizado. Utilizou-se o esquema de tratamentos em parcelas subdivididas, onde o tratamento principal foi a formulação e o secundário o tempo de armazenamento. Os resultados foram submetidos à Análise de Variância (ANOVA) e teste " $t$ " de comparação de médias $(p=0,05)$ no programa SAS 9.1.3 (SAS Institute Inc., Cary, NC).

\section{Resultados e Discussão}

$\mathrm{Na}$ tabela 1 estão apresentados os resultados para as características de $\mathrm{pH}$, acidez titulável e sinérese dos iogurtes desnatados probióticos durante armazenamento a $4^{\circ} \mathrm{C}$. 
Tabela 1. Características de $\mathrm{pH}$, acidez titulável e sinérese das formulações de iogurte desnatado probiótico durante armazenamento refrigerado a $4^{\circ} \mathrm{C}^{*}$

\begin{tabular}{cccccc}
\hline Características & $\begin{array}{c}\text { Tempo de } \\
\text { Estocagem } \\
\text { (Dias) }\end{array}$ & Normal & P95 & ST & HP \\
\hline & 1 & $4,45 \pm 0,01^{\mathrm{aA}}$ & $4,38 \pm 0,01^{\mathrm{bA}}$ & $4,45 \pm 0,02^{\mathrm{aA}}$ & $4,45 \pm 0,02^{\mathrm{aA}}$ \\
$\mathrm{pH}$ & 14 & $4,35 \pm 0,02^{\mathrm{aB}}$ & $4,26 \pm 0,01^{\mathrm{bB}}$ & $4,34 \pm 0,02^{\mathrm{aB}}$ & $4,34 \pm 0,02^{\mathrm{aB}}$ \\
& 28 & $4,24 \pm 0,01^{\mathrm{aC}}$ & $4,16 \pm 0,02^{\mathrm{bC}}$ & $4,23 \pm 0,02^{\mathrm{aC}}$ & $4,23 \pm 0,02^{\mathrm{aC}}$ \\
& & & & \\
& 1 & $1,11 \pm 0,04^{\mathrm{bB}}$ & $1,20 \pm 0,03^{\mathrm{aB}}$ & $1,11 \pm 0,01^{\mathrm{bB}}$ & $1,09 \pm 0,03^{\mathrm{bB}}$ \\
Acidez Titulável & 14 & $1,14 \pm 0,05^{\mathrm{bA}}$ & $1,27 \pm 0,03^{\mathrm{aA}}$ & $1,18 \pm 0,04^{\mathrm{bA}}$ & $1,15 \pm 0,04^{\mathrm{bA}}$ \\
$(\%$ de ácido lático) & 28 & $1,17 \pm 0,04^{\mathrm{bA}}$ & $1,25 \pm 0,03^{\mathrm{aA}}$ & $1,20 \pm 0,04^{\mathrm{bA}}$ & $1,17 \pm 0,03^{\mathrm{bA}}$ \\
& & & & & \\
Sinérese $(m L 100 \mathrm{~g}$ & 1 & $25,25 \pm 1,83^{\mathrm{aC}}$ & $23,91 \pm 0,51^{\mathrm{aC}}$ & $26,07 \pm 1,75^{\mathrm{aC}}$ & $23,98 \pm 2,65^{\mathrm{aC}}$ \\
produto $\left.^{-1}\right)$ & 14 & $28,47 \pm 0,20^{\mathrm{aB}}$ & $27,99 \pm 1,02^{\mathrm{aB}}$ & $28,20 \pm 1,34^{\mathrm{aB}}$ & $28,00 \pm 1,39^{\mathrm{aB}}$ \\
& 28 & $34,48 \pm 2,65^{\mathrm{aA}}$ & $36,94 \pm 0,52^{\mathrm{aA}}$ & $36,59 \pm 1,24^{\mathrm{aA}}$ & $35,87 \pm 0,55^{\mathrm{aA}}$ \\
\hline
\end{tabular}

*Médias \pm desvio padrão na mesma linha acompanhadas de letras minúsculas distintas indicam diferenças a $\mathrm{p} \leq 0,05$ entre as formulações de iogurte para o mesmo dia de estocagem. Médias \pm desvio padrão na mesma coluna acompanhadas de letras maiúsculas distintas indicam diferenças a $\mathrm{p} \leq 0,05$ para cada formulação afetada pelo tempo de armazenamento ( $\mathrm{n}=6$, exceto para sinérese $n=4)$

** Formulações: Normal (iogurte probiótico); P95 (iogurte probiótico+ frutano tipo inulina de baixo DP, oligofrutose); ST (iogurte probiótico + frutano tipo inulina de médio DP, inulina ST), HP (iogurte probiótico + frutano tipo inulina de alto DP, inulina HP)

Fonte: Elaboração dos autores.

O iogurte adicionado de frutano tipo inulina de baixo DP (formulação P95) apresentou menores valores de $\mathrm{pH}$ e maiores valores de acidez titulável $(p \leq 0,05)$ do que as demais formulações (Normal, ST e HP), as quais não foram diferentes entre si ( $>00,05)$. Oligofrutoses apresentam menor grau de polimerização do que a inulina e, portanto, maior quantidade de açúcares livres, como a glicose e a frutose. Os microorganismos das culturas lática e probiótica podem ter metabolizado os açúcares presentes e, como consequência, houve produção de pequenas quantidades de ácidos orgânicos (PERRIN et al., 2002; DING; SHAH, 2008). Os resultados indicam que a adição de inulina de médio e alto DP (formulações ST e HP) não altera a acidez de iogurtes, enquanto a adição de oligofrutose (baixo DP) resulta em produtos ligeiramente mais ácidos.

A acidez dos iogurtes (formulações Normal, P95, ST e HP) aumentou durante o período de armazenamento (menores valores de $\mathrm{pH}$ e maiores valores de acidez titulável), independentemente da adição de frutanos tipo inulina. O aumento da acidez é resultado da pós-acidificação dos produtos e está relacionado à continuidade do processo fermentativo pelas bactérias ácido-láticas durante o período de estocagem, com produção de ácido lático (APORTELA-PALACIOS; SOSA-MORALES; VÉLEZ-RUIZ, 2005). Os valores médios de $\mathrm{pH}$ das formulações situaram-se entre 4,45 e 4,16 durante o período de estocagem, corroborando estudos anteriores (ARYANA; McGREW, 2007; AKALIN et al., 2007). Os resultados para acidez titulável situaram-se entre 1,09 e 1,27\% de ácido lático durante o período de estocagem e atendem ao estabelecido pela legislação vigente (BRASIL, 2000), a qual afirma que iogurtes devem apresentar acidez mínima de 0,6 e máxima de 1,5 gramas de ácido lático por 100 gramas de produto.

A adição de frutanos tipo inulina de diferente DP (formulações P95, ST e HP) não alterou a sinérese dos produtos (formulação Normal) $(p>0,05)$. A sinérese representa um dos principais defeitos 
encontrados em iogurtes, sendo importante para a qualidade e aceitabilidade desses produtos pelos consumidores. Pelos resultados obtidos no presente estudo, é possível observar que a adição de frutanos tipo inulina não tem influência na separação de soro em iogurtes desnatados probióticos do tipo firme. Resultados semelhantes foram encontrados por Castro et al. (2009) e Mazloomi et al. (2011) para iogurtes adicionados de oligofrutose e inulina, respectivamente.

A sinérese aumentou $(\mathrm{p} \leq 0,05)$ durante o período de armazenamento em todas as formulações (Normal, P95, ST e HP), o que pode estar relacionado ao decréscimo do $\mathrm{pH}$ durante a estocagem (Tabela 1), o qual provoca a contração da matriz micelar de caseína, aumentando a expulsão de soro (ACHANTA; ARYANA; BOENECKE, 2007). Para Aportela-Palacios, Sosa-Morales e Vélez-Ruiz (2005), valores de sinérese abaixo de $39 \%$ podem ser considerados satisfatórios. Os valores médios obtidos neste estudo (23,9 a 36,9\%) se encontraram abaixo do recomendado.

$\mathrm{Na}$ tabela 2 estão apresentados os resultados para as características de firmeza e cor (parâmetros $L^{*}, a^{*}$ e b*) dos iogurtes desnatados probióticos durante armazenamento a $4^{\circ} \mathrm{C}$.

O iogurte adicionado de inulina de alto DP (formulação HP) apresentou menores valores de firmeza $(p \leq 0,05)$ do que as demais formulações (Normal, P95 e ST), as quais não foram diferentes entre si $(\mathrm{p}>0,05)$. A longa cadeia polissacarídica dessa inulina pode ter permanecido dispersa dentro das micelas de caseína, interferindo na formação da matriz protéica e sendo responsável por um gel mais macio (PASEEPHOL; SMALL; SHERKAT, 2008). Segundo Paseephol, Small e Sherkat (2008), o mesmo pode ser observado em iogurtes integrais, nos quais os glóbulos de gordura ficam dispersos dentro das micelas de caseína ocasionando a formação de géis menos firmes. Portanto, os resultados obtidos para firmeza neste estudo demonstram o possível papel da inulina de alto DP como substituto de gordura. A adição de frutanos tipo inulina de médio DP (formulação ST) ou baixo DP (formulação P95) não influenciou na firmeza dos produtos (formulação Normal) ( $\mathrm{p}>0,05)$.

A firmeza dos iogurtes desnatados probióticos (formulações Normal, P95, ST e HP) se manteve constante $(\mathrm{p}>0,05)$ durante o período de armazenamento. A estabilidade da firmeza é desejada, uma vez que, dessa forma, confirma-se que o produto após 28 dias continua semelhante ao produto recém-fabricado (MARUYAMA et al., 2006). Os valores médios encontrados para a firmeza dos iogurtes (1,65 a 1,85N) estão de acordo com os reportados por La Torre, Tamime e Muir (2003) e Kumar e Mishra (2003).

Não houve diferenças $(p>0,05)$ nos parâmetros $L^{*}, a^{*}$ e $b^{*}$ de cor entre as formulações e durante o período de estocagem. Um fator que influencia a cor do produto é a cor dos ingredientes utilizados em sua fabricação (ARYANA; McGREW, 2007). O leite em pó desnatado foi comum a todas as formulações e os tratamentos continham frutanos tipo inulina e cultura probiótica, na forma de pó, não alterando então a cor dos iogurtes. Aryana e McGrew (2007) e Mazloomi et al. (2011) também não observaram efeito da adição de frutanos tipo inulina nos parâmetros de cor de iogurtes

Os iogurtes apresentaram coloração clara (valores elevados de $\mathrm{L}^{*}$ ), amarelada (componente $\mathrm{b}^{*}$ positivo) e com tendência ao vermelho (componente $\mathrm{a}^{*}$ ligeiramente positivo) durante todo o período de armazenamento. Embora os iogurtes naturais visualmente pareçam brancos e brilhantes ao olho humano, o instrumento é mais sensível e foi capaz de captar a coloração amarela ligeiramente avermelhada dos produtos.

$\mathrm{Na}$ figura 1 está apresentada a viabilidade da cultura probiótica nos iogurtes desnatados probióticos durante armazenamento a $4^{\circ} \mathrm{C}$. 
Tabela 2. Características de firmeza e cor (parâmetros L*, $\mathrm{a}^{*}$ e $\mathrm{b}^{*}$ ) das formulações de iogurte desnatado probiótico durante armazenamento refrigerado a $4^{\circ} \mathrm{C}^{*}$.

\begin{tabular}{cccccc}
\hline Características** $^{*} \begin{array}{c}\text { Tempo de } \\
\text { Estocagem } \\
\text { (Dias) }\end{array}$ & Normal & P95 & ST & HP \\
\hline & 1 & $1,74 \pm 0,05^{\mathrm{aA}}$ & $1,79 \pm 0,07^{\mathrm{aA}}$ & $1,85 \pm 0,04^{\mathrm{aA}}$ & $1,65 \pm 0,08^{\mathrm{bA}}$ \\
Firmeza (N) & 14 & $1,79 \pm 0,16^{\mathrm{aA}}$ & $1,78 \pm 0,06^{\mathrm{aA}}$ & $1,78 \pm 0,13^{\mathrm{aA}}$ & $1,71 \pm 0,06^{\mathrm{bA}}$ \\
& 28 & $1,84 \pm 0,14^{\mathrm{aA}}$ & $1,78 \pm 0,03^{\mathrm{aA}}$ & $1,75 \pm 0,12^{\mathrm{aA}}$ & $1,84 \pm 0,05^{\mathrm{bA}}$ \\
& & & & \\
& 1 & $87,35 \pm 0,63^{\mathrm{aA}}$ & $86,53 \pm 0,54^{\mathrm{aA}}$ & $85,73 \pm 0,99^{\mathrm{aA}}$ & $85,08 \pm 2,01^{\mathrm{aA}}$ \\
$\mathrm{L}^{*}$ & 14 & $85,69 \pm 2,23^{\mathrm{aA}}$ & $86,47 \pm 0,77^{\mathrm{aA}}$ & $86,65 \pm 0,60^{\mathrm{aA}}$ & $86,29 \pm 1,52^{\mathrm{aA}}$ \\
& 28 & $86,50 \pm 0,36^{\mathrm{aA}}$ & $86,67 \pm 0,84^{\mathrm{aA}}$ & $86,27 \pm 0,45^{\mathrm{aA}}$ & $86,71 \pm 0,42^{\mathrm{aA}}$ \\
& & & & \\
$\mathrm{a}^{*}$ & 1 & $1,75 \pm 0,41^{\mathrm{aA}}$ & $1,84 \pm 0,33^{\mathrm{aA}}$ & $1,65 \pm 0,29^{\mathrm{aA}}$ & $1,61 \pm 0,26^{\mathrm{aA}}$ \\
& 14 & $1,70 \pm 0,16^{\mathrm{aA}}$ & $1,68 \pm 0,33^{\mathrm{aA}}$ & $1,70 \pm 0,38^{\mathrm{aA}}$ & $1,72 \pm 0,31^{\mathrm{aA}}$ \\
& 28 & $1,62 \pm 0,20^{\mathrm{aA}}$ & $1,73 \pm 0,11^{\mathrm{aA}}$ & $1,70 \pm 0,25^{\mathrm{aA}}$ & $1,61 \pm 0,10^{\mathrm{aA}}$ \\
& & & & & \\
& 1 & $11,41 \pm 0,80^{\mathrm{aA}}$ & $11,34 \pm 0,74^{\mathrm{aA}}$ & $11,48 \pm 0,86^{\mathrm{aA}}$ & $11,45 \pm 0,81^{\mathrm{aA}}$ \\
& 14 & $11,03 \pm 0,55^{\mathrm{aA}}$ & $11,18 \pm 0,75^{\mathrm{aA}}$ & $11,20 \pm 0,72^{\mathrm{aA}}$ & $11,22 \pm 0,78^{\mathrm{aA}}$ \\
& 28 & $10,95 \pm 0,52^{\mathrm{aA}}$ & $11,39 \pm 0,90^{\mathrm{aA}}$ & $11,03 \pm 0,69^{\mathrm{aA}}$ & $11,45 \pm 0,68^{\mathrm{aA}}$ \\
\hline
\end{tabular}

*Médias \pm desvio padrão na mesma linha acompanhadas de letras minúsculas distintas indicam diferenças a $\mathrm{p} \leq 0,05$ entre as formulações de iogurte para o mesmo dia de estocagem. Médias \pm desvio padrão na mesma coluna acompanhadas de letras maiúsculas distintas indicam diferenças a $\mathrm{p} \leq 0,05$ para cada formulação afetada pelo tempo de armazenamento $(\mathrm{n}=6)$

** $\mathrm{L}^{*}$ variando de 0 (preto) a 100 (branco); $\mathrm{a}^{*}$ variando do vermelho $\left(+\mathrm{a}^{*}\right)$ ao verde $\left(-\mathrm{a}^{*}\right)$; e b* variando do amarelo (+b*) ao azul $\left(-b^{*}\right)$

*** Formulações: Normal (iogurte probiótico); P95 (iogurte probiótico+ frutano tipo inulina de baixo DP, oligofrutose); ST (iogurte probiótico + frutano tipo inulina de médio DP, inulina ST), HP (iogurte probiótico + frutano tipo inulina de alto DP, inulina HP)

Fonte: Elaboração dos autores.

Figura 1. Viabilidade da cultura probiótica Lactobacillus paracasei ssp. paracasei nas formulações de iogurte: Normal (probiótica), P95 (probiótica + oligofrutose P95), ST (probiótica + inulina ST) e HP (probiótica + inulina HP), durante armazenamento refrigerado $\left(4^{\circ} \mathrm{C}\right)$. Dias de estocagem: $1(\square), 14(\square)$ e 28( $\left.\square\right)$. As barras de erro representam o desvio padrão $(n=4)$.

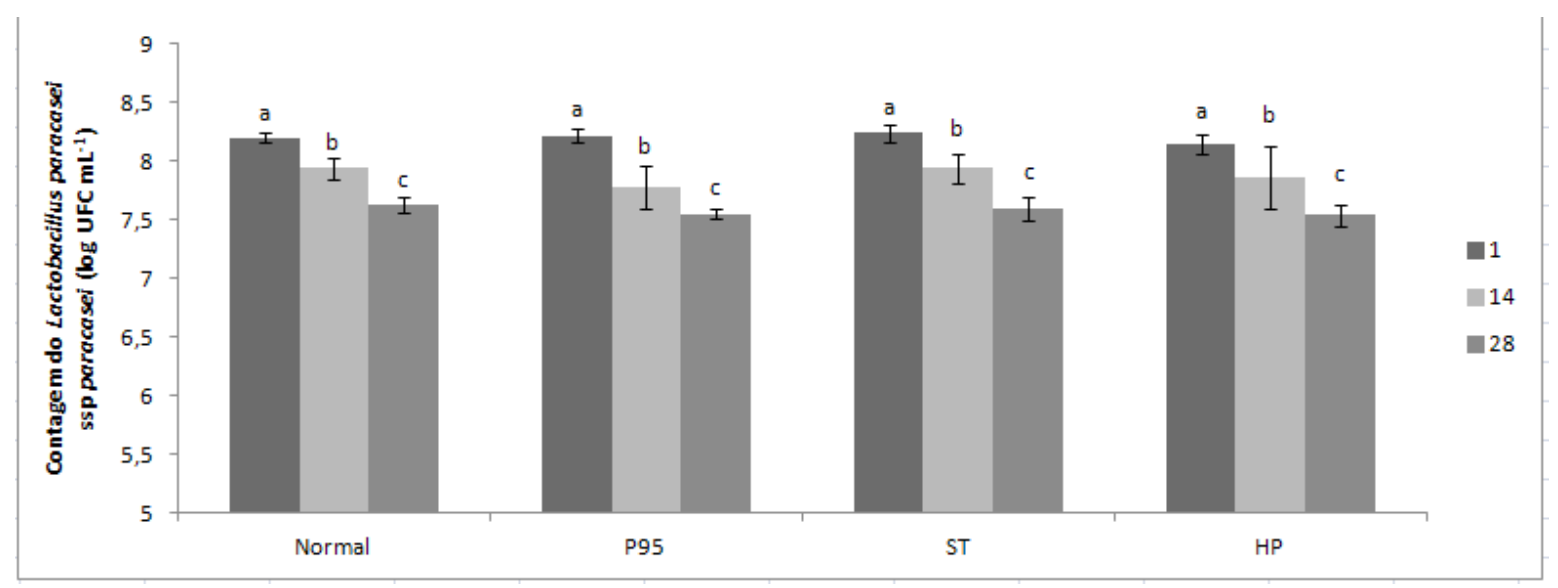

Fonte: Elaboração dos autores. 
A adição de frutanos tipo inulina de diferente DP (formulações P95, ST e HP) não teve influência $(\mathrm{p}>0,05)$ na viabilidade do probiótico Lactobacillus paracasei ssp. paracasei (formulação Normal), corroborando estudos anteriores (AKALIN et al., 2007; CARDARELLI et al., 2008; MAZLOOMI et al., 2011). No entanto, outros estudos encontraram efeito protetor de frutanos tipo inulina sobre bactérias probióticas, incluindo o aumento de sua sobrevivência e atividade durante a estocagem do produto (AKALIN; FENDERYA; AKBULUT, 2004; ARYANA; McGREW, 2007; DONKOR et al., 2007).

$\mathrm{O}$ efeito não significativo encontrado neste estudo pode estar relacionado à concentração dos frutanos utilizada (2\%); ao meio base (leite em pó); e à cepa empregada (Lactobacillus paracasei ssp. paracasei). Shin et al. (2000) reportaram que concentrações mínimas de 5\% de frutanos tipo inulina eram necessárias para observar um aumento significativo no tempo médio de duplicação e, consequentemente, na viabilidade dos probióticos. Fuchs et al. (2006) sugerem que a utilização de leite em pó gera um meio rico em lactose, que é o substrato preferencial das bactérias ácido-láticas, e que essa lactose poderia exercer o mesmo efeito protetor que os frutanos tipo inulina na viabilidade de culturas probióticas. Özer, Akin e Özer (2005) observaram que a adição de inulina aumentou a viabilidade de $B$. bifidum BB-02, mas não teve influência no crescimento de L. acidophilus La5 , demonstrando que o efeito protetor de frutanos tipo inulina é específico para cada cepa probiótica selecionada (DONKOR et al., 2007).

Houve uma diminuição significativa na contagem de Lactobacillus paracasei ssp. paracasei com o aumento no tempo de estocagem $(\mathrm{p} \leq 0,05)$, o que pode estar relacionada à diminuição do $\mathrm{pH}$ durante o armazenamento (Tabela 1). Tem sido reportado que o fator que mais contribui para a perda de viabilidade de culturas probióticas é o decréscimo do $\mathrm{pH}$ durante a estocagem (pós-acidificação) e o acúmulo de ácidos orgânicos, resultantes da continuação do processo fermentativo (SHAH, 2000). Ácidos orgânicos, como o lático e o acético, são poderosos agentes antimicrobianos e podem ter um papel fundamental na sobrevivência de culturas probióticas, sendo que maiores concentrações desses compostos resultam em menores contagens de probióticos (AKALIN; FENDERYA; AKBULUT, 2004).

No entanto, apesar de diminuições nas contagens, a viabilidade da cultura probiótica se manteve superior a $10^{7} \mathrm{UFC} \mathrm{mL}^{-1}$ durante todo o período de armazenamento, representando $10^{9}$ UFC em 100 gramas de produto. A legislação brasileira considera um alimento probiótico aquele que contém uma quantidade mínima viável da cultura probiótica na faixa de $10^{8}$ a $10^{9}$ UFC na porção diária (ANVISA, 2008). Portanto, para as formulações estudadas (Normal, P95, ST e HP), uma porção de 100 gramas diários já permitiria sua classificação como alimento probiótico. Internacionalmente, se considera como funcionais contagens superiores a $6 \log \mathrm{mL}^{-1}$ (DONKOR et al., 2007). Sendo assim, os iogurtes do presente estudo apresentaram viabilidade do probiótico acima do recomendado.

A alegação de propriedade funcional de frutanos tipo inulina é permitida desde que a porção diária do produto pronto para o consumo forneça no mínimo 1,5 gramas, em caso de alimentos líquidos (ANVISA, 2008). Teores de $2 \%$ de frutanos tipo inulina foram adicionados (formulações P95, ST e HP), indicando que seria possível a utilização da alegação de propriedade funcional para os iogurtes formulados, considerando uma porção diária de 100 gramas. Manning e Gibson (2004) recomendam a ingestão de 4 gramas diários de prebióticos para se obter os efeitos benéficos à saúde associados a esses componentes. Sendo assim, seria necessária a ingestão de 200 gramas diários do iogurte elaborado nesse estudo.

É importante mencionar que não foi realizada a quantificação dos prebióticos ao longo da estocagem, o que não permite inferir sobre a estabilidade 
destes ingredientes, ou seja, não é possível afirmar que os teores de frutanos tipo inulina adicionados inicialmente seriam encontrados nos produtos após o armazenamento refrigerado por 28 dias. No entanto, Pimentel, Garcia e Prudencio (2012) observaram uma redução de apenas $2,4 \%$ no conteúdo de inulina durante o armazenamento refrigerado $\left(4^{\circ} \mathrm{C}\right.$ por 28 dias) de iogurtes probióticos com inulina como substituto de gordura.

\section{Conclusões}

Conclui-se que o grau de polimerização de frutanos tipo inulina não afeta negativamente as características físico-químicas e microbiológicas dos iogurtes desnatados probióticos e sua estabilidade ao armazenamento; sendo assim, a seleção do tipo a ser utilizado dependerá do objetivo do fabricante e da intenção de uso, já que oligofrutoses podem ser utilizadas como substitutos de açúcar e a inulina como substituto de gordura.

\section{Referências}

ACHANTA, K.; ARYANA, K. J.; BOENECKE, C. A. Fat free plain set yogurts fortified with various minerals. LWT, Oxford, v. 40, n. 3, p. 424-429, 2007.

AKALIN, A. S.; GÖNÇ, G.; ÜNAL, G.; FENDERYA, S. Effects of fructooligosaccharide and whey protein concentrate on the viability of lactic culture in reducedfat probiotic yogurt during storage. Journal of Food Science, Chicago, v. 72, n. 7, p. 222-227, 2007.

AKALIN, A. S.; FENDERYA, S.; AKBULUT, N. Viability and activity of bifidobacteria in yoghurt containing fructooligosaccharide during refrigerated storage. International Journal of Food Science and Technology, Oxford, v. 39, n. 6, p. 613-621, 2004.

AGÊNCIANACIONAL DE VIGILÂNCIA SANITÁRIA - ANVISA. Alimentos. Alimentos com alegações de propriedades funcionais e ou de saúde, novos alimentos/ ingredientes, substâncias bioativas e probióticos. Atualizado em julho de 2008. IX - Lista das alegações de propriedades funcionais aprovadas. 2008. Disponível em: $\quad<$ http://www.anvisa.gov.br/alimentos/comissoes/ tecno.htm>. Acesso em: 17 fev. 2011.
APORTELA-PALACIOS, A.; SOSA-MORALES, M. E.; VÉLEZ-RUIZ, J. F. Rheological and physicochemical behavior of fortified yogurt, with fiber and calcium. Journal of Texture Studies, Trumbull, v. 36, n. 3, p. 333349, 2005.

ARYANA, K. J. Folic acid fortified fat-free plain set yoghurt. International Journal of Dairy Technology, Huntingdon, v. 56, n. 4, p. 219-222, 2003.

ARYANA, K. J.; McGREW. P. Quality attributes of yogurt with Lactobacillus casei and various prebiotics. LWT, Oxford, v. 40, n. 10, p. 1808-1814, 2007.

ASSOCIATION OF OFFICIAL ANALYTICAL CHEMISTRY - AOAC. Official methods of analysis of AOAC International. 16. ed. Arlington, 1995. v. 2.

BRASIL, Ministério da Agricultura, Pecuária e Abastecimento e da Reforma Agrária, Resolução n ${ }^{\circ} 5$ de13 de novembro de 2000. Oficializa os "Padrões de Identidade e Qualidade (PIQ) de Leites Fermentados. Diário Oficial [da] República Federativa do Brasil, Brasília, 2000.

CARDARELLI, H. R.; BURITI, F. C.; CASTRO, I. A.; SAAD, S. M. I. Inulin and oligofructose improve sensory quality and increase the probiotic viable count in potentially synbiotic petit-suisse cheese. $L W T$, Oxford, v. 41, n. 6, p. 1037-1046, 2008.

CASTRO, F. P.; CUNHA, T. M.; OGLIARI, P. J.; TEÓFILO, R. F.; FERREIRA, M. M. C.; PRUDÊNCIO, E. S. Influence of different content of cheese whey and oligofructose on the properties of fermented lactic beverages: study using response surface methodology. LWT, Oxford, v. 42, n. 5, p. 993-997, 2009.

COUSSEMENT, P. A. A. Inulin and oligofructose: safe intakes and legal status. Journal of Nutrition, Bethesda, v. 129, n. 7, p. 1412-1417, 1999.

CRUZ, A. G.; CADENA, R. S.; WALTER, E. H. M.; MORTAZAVIAN, A. M.; GRANATO, D.; FARIA, J. A. F.; BOLINI, H. M. A. Sensory analysis: relevance for prebiotic, probiotic, and synbiotic product development. Comprehensive Reviews in Food Science and Food Safety, Malden, v. 9, n. 4, p. 358-373, 2010.

DE LUIS, D. A.; DE LA FUENTE, B.; IZAOLA, O.; CONDE, R.; GUTIERRÉZ, S.; MORILLO, M.; TORRES, C. T. Double blind randomized clinical trial controlled by placebo with an alpha linoleic acid and prebiotic enriched cookie on risk cardiovascular factor in obese patients. Nutrición Hopitalaria, Madrid, v. 24, n. 4, p. 827-833, 2011. 
DING, W. K.; SHAH, N. P. Survival of free and microencapsulated probiotic bacteria in orange and apple juices. International Food Research Journal, Selangor, v. 15, n. 2, p. 219-232, 2008.

DONG, H.; ROWLAND, I.; TUOHY, K. K.; THOMAS, L. V.; YAQOOB, P. Selective effects of Lactobacillus casei Shirota on $\mathrm{T}$ cell activation, natural killer cell activity and cytokine production. Clinical and Experimental Immunology, London, v. 161, n. 2, p. 378388, 2010.

DONKOR, O. N.; NILMINI, S. L. I.; STOLIC, P.; VASILJEVIC, T.; SHAH, N. P. Survival and activity of selected probiotic organisms in set-type yoghurt during cold storage. International Dairy Journal, Edmonton, v. 17, n. 6, p. 657-665, 2007.

FAO/ AGNS. FAO Technical Meeting Report on Prebiotics. 2007. Avaliado em: <http://www.fao.org/ag/ agn/agns/files/Prebiotics_Tech_Meeting_Report.pdf $\geq$. Acesso em: 15 set. 2011.

FAO/WHO. Evaluation of health and nutritional properties of probiotics in food including powder milk with live lactic acid bacteria. 2001. Report of a joint FAO/WHO expert consultation, Córdoba, Argentina. Acesso em: <ftp://ftp.fao.org/docrep/fao/meeting/009/ y6398e.pdf $>$. Acesso em: 15 set. 2011.

FRANCK, A. Technological functionality of inulin and oligofructose. British Journal of Nutrition, London, v. 87, n. 2, p. 287-291, 2002.

FUCHS, R. H. B.; TANAMATI, A. A. C.; ANTONIOLI, C. M.; GASPARELLO, E. A.; DONEDA, I. Utilização de Lactobacillus casei e cultura iniciadora na obtenção de iogurte suplementado com inulina e oligofrutose. Boletim Ceppa, Curitiba, v. 24, n. 1, p. 83-98, 2006.

GUÉRIN-DANAN, C.; MESLIN, J-C.; CHAMBARD, A.; CHAEPILIENNE, A.; RELANO, P.; BOUlEY, C.; COHEN, J.; ANDRIEUX, C. Food supplementation with milk fermented by Lactobacillus casei DN-114 011 protects suckling rats from rota-virus associated diarrhea. Journal of Nutrition, Bethesda, v. 131, n. 1, p. 111-117, 2001.

INGRASSIA, I.; LEPLINGARD, A.; DARFEUILLEMICHAUD, A. Lactobacillus casei DN-114 001 inhibits the ability of adherent-invasive Escherichia coli isolated from Crohn's disease patients to adhere to and to invade intestinal epithelial cells. Applied and Environmental Microbiology, Washington D.C, v. 71, n. 6, p. 2880-2887, 2005.

KAUR, N.; GUPTA, A. K. Applications of inulin and oligofructose in health and nutrition. Journal of Biosciences, Bangalore, v. 27, n. 7, p. 703-714, 2002.
KELLY, G. Inulin-type prebiotics - a review: (Part 1). Alternative Medicine Review, Saindpoint, v. 13, n. 4, p. 315-329, 2008.

KUMAR, P.; MISHRA, H. N. Effect of mango pulp and soymilk fortification on the texture profile of set yoghurt made from buffalo milk. Journal of Texture Studies, Trumbull, v. 34, n. 3, p. 249-269, 2003.

LA TORRE, L.; TAMIME, A. Y.; MUIR, D. D. Rheology and sensory profiling of set-style fermented milks made with different commercial probiotic and yoghurt lactic cultures. International Journal of Dairy Technology, Huntingdon, v. 56, n. 3, p. 163-170, 2003.

MANNING, T. S.; GIBSON, G. R. Prebiotics. Best Practice \& Research Clinical Gastroenterology, London, v. 18, n. 2, p. 287-298, 2004.

MARUYAMA, L. W.; CARDARELLI, H. R.; BURITI, F. C. A.; SAAD, S. M. I. Textura instrumental de queijo petit-suisse potencialmente probiótico: influência de diferentes combinações de gomas. Revista Ciência e Tecnologia de Alimentos, Campinas, v. 26, n. 2, p. 386393, 2006.

MAZLOOMI, S. M.; SHEKARFOROUSH, S. S.; EBRAHIMNEJAD, H.; SAJEDIANFARD, J. Effect of adding inulin on microbial and physicochemical properties of low fat probiotic yoghurt. Iranian Journal of Veterinary Research, Shiraz, v. 12, n. 2, p. 93-98, 2011.

MINELLI, E. B.; BENINI, A.; MARZOTTO, M.; SBARBATI, A.; RUZZENENTE, O.; FERRARIO, R.; HENDRIKS, H.; DELLAGLIO, F. Assesment of novel probiotic Lactobacillus casei strains for the production of functional dairy foods. International Dairy Journal, Edmonton, v. 14, n. 8, p. 723-736, 2004.

MONADI, A. R.; MIRZAEI, H.; JAVADI, A.; HOSSEINZADE, N.; AMJADI, Y. Effect of some probiotics on Salmonella typhi during associated growth in milk. African Journal Microbiology Research, Nigeria, v. 4, n. 24, p. 2708-2711, 2010.

NINESS, K. R. Inulin and Oligofructose: what are they? Journal of Nutrition, Bethesda, v. 129, n. 7, p. 14021406, 1999.

ÖZER, D.; AKIN, S.; OZER, B. Effect of inulin and lactulose on survival of Lactobacillus acidophilus La-5 and Bifidobacterium bifidum BB-02 in acidophilusbifidus yoghurt. Food Science and Technology, London, v. 11, n. 1, p. 19-26, 2005.

PASEEPHOL, T.; SMALL, D. M.; SHERKAT, F. Rheology and texture of set yogurt as affected by inulin addition. Journal of Texture Studies, Trumbull, v. 39, n. 6, p. 617-634, 2008. 
PERRIN, S.; FOUGNIES, C.; GRILL, J. P.; JACOBS, H.; SCHNEIDER, F. Fermentation of chicory fructooligosaccharides in mixtures of different degrees of polymerization by three strains of bifidobacteria. Canadian Journal of Microbiology, Ottawa, v. 48, n. 8, p. 759-763, 2002.

PIMENTEL, T.; GARCIA, S.; PRUDENCIO, S. H. Effect of long-chain inulin on the texture profile and survival of Lactobacillus paracasei ssp. paracasei in set yoghurts during refrigerated storage. International Journal of Dairy Technology, Huntingdon, v. 65, n. 1, p. 104-110, 2012.

ROBERFROID, M. B. Introducing inulin-type fructans. British Journal of Nutrition, London, v. 93, n. 1, p. 1325, 2005.

SANDERS, M. E. Probiotics: considerations for human health. Nutrition Reviews, New York, v. 61, n. 3, p. 9199, 2003.

SAXELIN, M.; KORPELA, R.; MAYRA-MAKINEN, A. Introduction: classifying functional dairy products. In: MATTILA-SANDHOLM, T.; SAARELA, M. (Ed.). Functional dairy products. Boca Raton, LA, USA: CRC Press, 2003. cap. 1, p. 1-16.

SGOURAS, D.; MARAGKOUDAKIS, P. A.; PETRAKI, K.; MARTINEZ-GONZALEZ, B.; ERIOTOU, E.; MICHOPOULOS, S.; KALANTZOPOULOS, G.; TSAKALIDOU, E.; MENTIS, A. In vitro and in vivo inhibition of Helicobacter pylori by Lactobacillus casei strain Shirota. Applied and Environmental Microbiology, Washington D.C, v. 70, n. 1, p. 518-526, 2004.
SHAH, N. P. Probiotic bacteria: selective enumeration and survival in dairy foods. Journal of Dairy Science, Champaign, v. 83, n. 4, p. 894-907, 2000.

SHEIL, B.; SHANAHAN, F.; O'MAHONY, L. Probiotic effects on inflammatory bowel disease. Journal of Nutrition, Bethesda, v. 137, n. 3, p. 819-824, 2007.

SHIN, H.-S.; LEE, J.-H.; PETSKA, J. J.; USTUNOL, Z. Growth and viability of commercial Bifidobacterium spp in skim milk containing oligosaccharides and inulin. Journal of Food Science, Chicago, v. 65, n. 5, p. 884-887, 2000.

TÁRREGA, A.; COSTELL, E. Effect of inulin addition on rheological and sensory properties of fat-free starchbased dairy desserts. International Dairy Journal, Edmonton, v. 16, n. 9, p. 1104-1112, 2006.

THARMARAJ, N.; SHAH, N. P. Selective enumeration of Lactobacillus delbrueckii ssp. bulgaricus, Streptococcus thermophilus, Lactobacillus acidophilus, Bifidobacteria, Lactobacillus casei, Lactobacillus rhamnosus, and Propionibacteria. Journal of Dairy Science, Champaign, v. 86, n. 7 , p. 2288-2296, 2003.

VAZ, R. T. C.; LOBO, A. R.; COCATO, M. L.; COLLI, C. Effects of inulin-type fructans consumption on mineral intestinal absorption and balance in rats fed control and iron-deficient diets. Alimentos e Nutrição, Araraquara, v. 21, n. 1, p. 7-13, 2010. 
